\title{
Level of Obesity and Prevalence of Diabetes Among Children and Adolescents of Some Affluent Families of Bangladesh
}

\author{
KC Bhuyan* \\ Professor of Statistics, Jahangirnagar University, Bangladesh \\ *Corresponding author: KC Bhuyan, Professor of Statistics, Jahangirnagar University, Dhaka, Bangladesh. \\ To Cite This Article: KC Bhuyan. Level of Obesity and Prevalence of Diabetes Among Children and Adolescents of Some Affluent Families of \\ Bangladesh. Am J Biomed Sci \& Res. 2019 - 4(1). AJBSR.MS.ID.000757. DOI: 10.34297/AJBSR.2019.04.000757
}

Received: June 17, 2019 | Published: July 17, 2019

\begin{abstract}
The present analysis was based on data collected from 662 children and adolescents of 560 families of students of American International University - Bangladesh. The children and adolescents were classified by level of obesity, where level of obesity was measured by percentiles of BMI. It was observed that, among 662 children and adolescents 465 were in underweight group. Obesity and severe obesity were observed among 9.1 percent children and adolescents. A big (38.1\%) group of obese children were suffering from diabetes. Obesity and prevalence of diabetes were significantly associated.
\end{abstract}

The present analysis was done to identify the most responsible variables for obesity and diabetes. The identification was done by performing factor analysis and discriminant analysis. The detected responsible variables were parents' education, occupation, family income, food habit of the child and utilization of time by the child.

Keywords: Level of Obesity; Prevalence of Diabetes; Factor Analysis; Discriminant Analysis; Identification of Responsible Variables for Obesity; Prevalence of Diabetes.

\section{Introduction}

Child obesity is a condition where excess body fat negatively affects a child's health or well-being and creates calorie imbalance [1]. Trends in obesity are causing serious public health problem throughout the world [2]. It is a threat to the viability of basic health care delivery. It is an independent risk factor for many noncommunicable diseases like diabetes, non-alcoholic fatty liver disease, cardiovascular disease risk, osteoarthritis and cancer. A global epidemic of pediatric obesity occurred in recent years, and prevalence of obesity is continuing to rise [3]. In the developed world obesity is now the most common disease of childhood and adolescence.

In Bangladesh also, the increasing prevalence of overweight and obesity among children ( 0 -12 years ) and adolescents (13-19 years) have emerged as a major public health problem [4] and it was observed that the prevalence of overweight and obesity among children and adolescents varied from $1.0 \%$ to $20.6 \%$ and 0.35 to $25.6 \%$, respectively. The pooled prevalence rates of overweight and obesity were $7.0 \%$ and $6.0 \%$, respectively. However, it is in increasing trend. Approximately, 43 million pre-school age children throughout the world have been estimated to be overweight and obese and 92 million are considered to be at risk of overweight [5].

Children who are obese are at a significantly elevated risk for adverse health outcomes including both medical and psychological problems [6]. The most common medical co-morbidities associated with obesity include metabolic risk factors for type II diabetes (T2D) including high blood pressure, high cholesterol, impaired glucose tolerance and metabolic syndrome [7,8]. Behavioral factors have significant effects on metabolic risk. It has been observed in some research findings that youth who do not meet guidelines for dietary behavior, physical activity and sedentary behavior have greater insulin resistance than those who do meet guidelines [9].

Psychological correlates of obesity create problems both in the family and in the society. The problems include reduced quality of life, low self-esteem social isolation and discrimination [10-12]. Depressed mood has been associated with greater risk of obesity and higher BMI [13]. The short and long term medical and psychological effects of childhood obesity have adverse consequences including increased morbidities and early mortality in adulthood [11,13]. A 
prospective study on adolescents revealed that as young adults, women particularly had an increased risk of social and economic difficulties [14]. Obesity has been attributed to various factors including genetics, environment, metabolism, behavior, personal history of obesity, culture and socio-economic status [9]. The origins of obesity can be traced to early adiposity rebound, which refers to the time at which BMI of young children begins to increase after reaching their lowest level of fat. Children in whom adiposity rebound begins at age of three years tend to have an increased mean BMI from age 3 to adolescence, which often extends into adulthood $[14,15]$. Children born to overweight or obese mothers are more likely to be overweight by the age of four years old even if their BMI is within the average range at the age of two years [16]. Other aspects of family environment are also highly influential [1]. Parents' knowledge about nutrition and physical activity has also been found to be very strong predictors of children's weight status [17]. In a study [18], among school-aged children it was observed that parental behavior and BMI have stronger impact on children's BMI. Features of the built environment, including excess to parks, supermarkets, and convenient store hours, have been found to moderate treatment effects of obesity intervention [19]. Proximity of a person's home to fast food restaurants has been associated with increased obesity rates [20].

Living in low-income neighborhoods has also been associated with more sedentary behavior and less physical activity [21]. School activity affects physical activity in youth. It has observed that children in higher socioeconomic schools have more excess to regular physical education classes than children attending low socioeconomic schools [22]. Therefore, it can be concluded that environmental factors are associated with physical activity and indirectly are associated with overweight and obesity. Besides, family and school-based interventions, medical treatment, etc. can prevent overweight and obesity among children and youth and ultimately the disease like diabetes, non-alcoholic fatty liver disease, cardiovascular disease risk, osteoarthritis and cancer.

Considering all of the associations of childhood obesity as discussed above, the objective of the present study was to identify the socioeconomic factors associated with overweight and obesity among children and youth under the age of 18 years who belonged to privileged families. The specific objectives were:

a) To study the association between level of obesity and prevalence of diabetes among children and adolescents of affluent families,

b) To identify the factors responsible for different levels obesity among children and adolescents of affluent families,

c) To discriminate the children and adolescents according to differentlevels of obesity and according to prevalence of diabetes so that important factors responsible for discrimination can be identified.

\section{Methodology}

The present analysis was based on 662 responses observed from 560 randomly selected affluent [23-26] families of students of American International University - Bangladesh during Summer 2016-17 semester. During the semester there were 9488 students in the university. In a previous study [4] it was reported that there were $7 \%$ overweight and obese children and adolescents in Bangladesh. Accordingly, we had decided to have a proportion of at least $7 \%$ overweight and obese children and youth with margin of error of $2 \%$ with $95 \%$ confidence in our study. To have such an estimate it required a sample of students of size $n$, where $n=\left(z^{\wedge} 2\right.$ $\mathrm{pq}) / \mathrm{d}^{\wedge} 2=625$ [ proportion of expected obese and overweight children and youth, $\mathrm{p}=0.07, \mathrm{q}=0.93$, margin of error, $\mathrm{d}=0.02$, normal ordinate for $95 \%$ confidence , $\mathrm{z}=1.96]$.

This sample size covered $6.6 \%$ students of the university. The sample students were selected by simple random sampling method and were expecting at least responses from 5\% families of the students. However, information was received from 560 families, covering the data of 662 children.

The data were collected through pre-designed and pre-tested printed questionnaire covering the questions related to the demographic characteristics of the children and youth of age below 18 years and the questions related to the socioeconomic variables of the parents. The randomly selected students were given written instructions how to collect information and they were requested to help in collecting information from their parents, who were very much concerned about the health hazard of their offspring. The children's fathers / mothers filled in the questionnaires as they were under 18 years of age and some were even below 10 years. The important collected information was age, height, weight, sex, food habit, time spent, involvement in co-curricular activities, if it is feasible, of the children and family income were also collected. For youth having diabetes, the latest blood sugar level measured by registered practitioner or measured in a registered clinic also recorded. Association of level of obesity and prevalence of diabetes was examined using chi-square test, where significant association was concluded when $p$-value $\leq 0.05$. In other studies $[24,25]$ it was observed that both level of obesity and prevalence of diabetes were significantly associated with some of the socio-demographic variables of respondents and their parents. But the study of association did not identify the most important variables for the variation in the levels of obesity and prevalence of diabetes. The importance of variables can be identified by factor analysis and by discriminant analysis [25-28]. In this paper factor analysis was done to identify the most responsible variables for different levels of obesity. Discriminant analysis was performed to discriminate the children and adolescents by their level of obesity. This analysis gave an idea about the importance of the variables in discriminating $[23,24,28]$ the children and adolescents by their level of obesity and by the prevalence of diabetes. The variables used in discriminant analysis and in factor analysis were age of children and adolescents, their food habit, utilization of time, parent's education, parent's occupation, and monthly family income, residence and religion. Some of the variables were qualitative in character. These variables were transformed to nominal scale by assigning number for the purpose of analysis. 


\section{Results}

The data provided the information that among 662 children and adolescents 70.2 percent were underweight and 23.4 percent of them were diabetic. There were 6.3 percent obese children and adolescents but 38.1 percent of them were diabetic. Only 2.8 percent respondents were severely obese, and diabetes prevailed in only 16.7 percent of them. However, these differential proportions of prevalence of -diabetes among the respondents of different levels of obesity were significantly different $X^{2}=8.741$, $\mathrm{p}$-value $=0.033$ ] The coefficient of association was 0.0133 . The value of odd ratio was 2.21 which indicated that those who were obese they were 2.21 times more exposed to diabetes compared to other groups having other levels of obesity (Table 1).

Table 1: Distribution of children and adolescents according to their level of obesity and prevalence of diabetes.

\begin{tabular}{|c|c|c|c|c|c|c|}
\hline \multirow{3}{*}{ Level of obesity } & \multicolumn{4}{|c|}{ Prevalence of diabetes } & \multirow{2}{*}{\multicolumn{2}{|c|}{ Total }} \\
\hline & \multicolumn{2}{|c|}{ Yes } & \multicolumn{2}{|c|}{ No } & & \\
\hline & $\mathbf{n}$ & $\%$ & $\mathbf{n}$ & $\%$ & $\mathbf{N}$ & $\%$ \\
\hline Underweight & 109 & 23.4 & 356 & 76.6 & 465 & 70.2 \\
\hline Overweight & 23 & 16.8 & 114 & 83.2 & 137 & 20.7 \\
\hline Obese & 16 & 38.1 & 26 & 61.9 & 42 & 6.3 \\
\hline Severe Obesity & 3 & 16.7 & 15 & 83.3 & 18 & 2.8 \\
\hline Total & 151 & 22.8 & 511 & 77.2 & 662 & 100 \\
\hline
\end{tabular}

Since the socio-demographic variables of the study group of children were associated with level of obesity and prevalence of diabetes $[24,25]$, let us detect the important variables for changes in level of obesity and changes in prevalence of diabetes. The detection can be done by factor analysis and discriminant analysis. Factor analysis was done separately for overweight, obese and severe obese group of children and adolescents. For the selection of components, the eigenvalues were considered up to 1.5. As a result, in each step three components were detected, where first component explained most of the variation in the data set.

The first factor analysis was done for the obese group of children. During analysis we had three eigen values giving the results up to 1.50 . So, we had 3 components. In each analysis the variables included were residence, religion, age of children, gender of children, parents' education and occupation, monthly family income, food habit of the children, utilization of time by the children and prevalence of diabetes. Three factor analyses were performed and for each one the justification of inclusion of variables was investigated by KMO statistic. For the first factor analysis for obese children the value of $\mathrm{KMO}=0.621$ giving $\chi^{2}$ $=488.069$, $p$-value $=0.000$. This result was in favor of inclusion of the variables to explain maximum variation in the data set. We had three components which explained 53.16 percent variation in the data set. But first component explained 24.98 percent variation. The other results were shown in (Table 2).

Table 2: Analytical results of factor analysis for overweight group of respondents.

\begin{tabular}{|c|c|c|c|c|}
\hline Variable & Communality & Coefficient of component - 1 & Coefficient of Component - 2 & Coefficient of component - 3 \\
\hline Residence & 0.65 & 0.143 & -0.573 & 0.488 \\
\hline Religion & 0.613 & -0.753 & 0.186 & 0.041 \\
\hline Age of child & 0.602 & -0.175 & 0.243 & 0.492 \\
\hline Gender & 0.721 & -0.212 & 0.498 & -0.643 \\
\hline Father's education & 0.785 & 0.784 & 0.382 & -0.002 \\
\hline Father's occupation & 0.505 & 0.259 & -0.443 & -0.015 \\
\hline Mother's education & 0.797 & 0.631 & 0.61 & 0.34 \\
\hline Mother's occupation & 0.639 & 0.163 & 0.132 & 0.151 \\
\hline Family income & 0.764 & -0.614 & 0.348 & 0.521 \\
\hline Food habit of child & 0.667 & 0.624 & 0.023 & -0.222 \\
\hline Utilization of time by the \\
child
\end{tabular}

The analytical results showed that the variables religion, father's education, family income, food habit of the children and adolescents, and utilization of time by the subject were the responsible variables for the overweight of the children. The most responsible variable was father's education followed by religion.
The next analysis was done for the obese group of children. The value of $\mathrm{KMO}=0.604, \chi^{2}=1069.04$ with $\mathrm{p}$-value $=0.000$. This indicated that to identify the responsible variables the included variables in the analysis were sufficient. In this case also three components were considered corresponding to minimum value of 
$\lambda=1.50$. The three identified components explained 46.77 percent variation in the data set. The first component explained 22.85 percent of the variation. The other results of the analysis were presented in (Table 3). It was observed that the most responsible variable for obesity of the children and adolescents was mother's education followed by father's education and father's occupation.

Table 3: Analytical results of factor analysis for obese group of respondents.

\begin{tabular}{|c|c|c|c|c|}
\hline Variable & Communality & Coefficients of component - 1 & Coefficient of component - 2 & Coefficients of component 3 \\
\hline Residence & 0.593 & -0.349 & 0.118 & -0.085 \\
\hline Religion & 0.603 & -0.125 & 0.144 & -0.315 \\
\hline Age of child & 0.642 & -0.026 & 0.04 & 0.68 \\
\hline Gender & 0.489 & 0.031 & 0.387 & -0.466 \\
\hline Fathers education & 0.778 & 0.817 & -0.105 & 0.006 \\
\hline Father's occupation & 0.625 & 0.702 & 0.24 & -0.191 \\
\hline Mother's education & 0.721 & 0.821 & 0.005 & -0.081 \\
\hline Mother's occupation & 0.667 & 0.236 & 0.547 & 0.457 \\
\hline Family income & 0.654 & 0.624 & -0.16 & 0.433 \\
\hline Food habit of child & 0.674 & 0.33 & 0.549 & -0.139 \\
\hline $\begin{array}{c}\text { Utilization of time by the } \\
\text { child }\end{array}$ & 0.648 & -0.351 & 0.045 & 0.339 \\
\hline Prevalence of diabetes & 0.739 & 0.301 & -0.772 & -0.176 \\
\hline
\end{tabular}

The last factor analysis was done for the subjects who were severe obese. Here $\mathrm{KMO}=0.308, \quad \chi^{2}=211.376, \mathrm{p}$-value $=0.000$. The minimum eigenvalue was observed 1.69 which was within the restriction of 1.5 and we had three components explaining 59.617 percent variation in the data set. The first component explained 24.204 percent variation of the data set. The other results were shown below: From the coefficients of the first component it was observed that the family income was the most (Table 4).

\begin{tabular}{|c|c|c|c|c|}
\hline Table 4: Analytical results of factor analysis for severe obese group of respondents. \\
\hline Variable & Communality & Coefficients of component- 1 & Coefficients of component - 2 & Coefficients of component - 3 \\
\hline Residence & 0.754 & -0.708 & -0.048 & 0.342 \\
\hline Religion & 0.833 & -0.436 & 0.194 & 0.362 \\
\hline Age of child & 0.811 & 0.708 & -0.18 & -0.442 \\
\hline Gender & 0.823 & -0.223 & -0.065 & 0.342 \\
\hline Father's education & 0.909 & 0.533 & 0.624 & 0.246 \\
\hline Fathers occupation & 0.618 & 0.239 & 0.382 & 0.425 \\
\hline Mother's education & 0.794 & 0.517 & 0.632 & 0.261 \\
\hline Mother's occupation & 0.752 & -0.056 & 0.235 & 0.341 \\
\hline Family income & 0.75 & -0.136 & 0.806 & -0.25 \\
\hline Food habit of child & 0.856 & 0.836 & -0.104 & 0.321 \\
\hline Utilization of time by the & 0.755 & -0.055 & 0.462 & -0.715 \\
\hline child & 0.751 & -0.575 & 0.613 & -0.174 \\
\hline Prevalence of diabetes & & & \\
\hline
\end{tabular}

responsible variable for the severe obesity among the children and adolescents followed by residence and age of the children. It had been noted that different types of variable were responsible for different levels of obesity. At this stage most important variable (s) needs to be detected. This can be done by discriminant analysis, where discrimination can be done among the different groups of respondents according to different levels of obesity. The analytical results were presented in (Table 5).

We had two discriminant functions. From the analysis it was noted that the value of Wilk's $=0.719$ for first function and it was 0.938 for second function. The corresponding $\chi^{2}$ was 208.987 and 40.902. for each one the $\mathrm{p}$-value $=0.000$. It indicated that the variable values of groups of respondents according to level of obesity were significantly different. Box's M = 973.611 which gave $\mathrm{F}=5.799$ with $\mathrm{p}$-value $=0.000$. The first function discriminated well between underweight and overweight group of respondents. The most responsible variable for discrimination was family income followed by father's education and residence. The second function discriminated well between obese and severe obese group of respondents. The most responsible variable for this discrimination was religion followed by father's education and mother's education. The variables food habit, utilization of time and BMI were also important to discriminate the two groups. These were observed from the significant correlation coefficients of variables and discriminant scores. The results of coefficients of functions were presented in (Table 5). 


\begin{tabular}{|c|c|c|c|c|}
\hline Table 5: Results of discriminant analysis according to level of obesity. \\
\hline Variable & Coefficients of function 1 & Coefficients of function 2 & $\begin{array}{c}\text { Correlation coefficients } \\
\text { related to function 1 }\end{array}$ & $\begin{array}{c}\text { Correlation coefficients } \\
\text { related to function 2 }\end{array}$ \\
\hline Residence & 0.112 & -0.005 & $0.143^{*}$ & 0.009 \\
\hline Religion & 0.342 & 0.314 & 0.352 & $0.536^{*}$ \\
\hline Age of child & -0.108 & -0.019 & -0.077 & $-0.085^{*}$ \\
\hline Gender & 0.303 & 0.593 & 0.374 & 0.622 \\
\hline Father's education & -0.171 & -0.266 & -0.189 & $-0.307^{*}$ \\
\hline Father's occupation & -0.558 & 0.148 & $0.415^{*}$ & 0.043 \\
\hline Mother's education & 0.483 & -0.173 & 0.035 & $-0.262^{*}$ \\
\hline Mother's occupation & 0.059 & 0.063 & $-0.154^{*}$ & 0.103 \\
\hline Family income & -0.541 & 0.373 & $-0.432^{*}$ & 0.297 \\
\hline Food habit of child & -0.031 & 0.05 & -0.012 & $-0.028^{*}$ \\
\hline Utilization of time by the \\
child
\end{tabular}

* Indicates importance of the variables.

Let us now observe the detection of the responsible variables for prevalence of diabetes. This was first done by the factor analysis and then by discriminant analysis. Factor analysis was done for the subjects of diabetic group. Here also the same group of variables was used for both factor analysis and discriminant analysis. The included variables for factor analysis was sufficient as $\mathrm{KMO}=0.772$ showing $\chi^{2}=707.44$ with $\mathrm{p}$-value $=0.000$. The eigenvalue greater than or equal to 1.50 was 4.37 . So, one component was derived which explained 36.447 percent variation in the data set related to prevalence of diabetes. The significant variable responsible for diabetic group of respondents was body mass index (BMI) followed by mother's education and father's education. These were observed from the maximum value of the coefficients of component. However, the most responsible variable was detected by discriminant analysis and it was detected from the results of the absolute highest correlation coefficients of the variable and discriminant score $[27,28]$. The results of the factor analysis and discriminant analysis were presented in (Table 6).

Table 6: Results of factor analysis and discriminant analysis according to prevalence of diabetes.

\begin{tabular}{|c|c|c|c|c|}
\hline Variable & $\begin{array}{c}\text { Communality for factor } \\
\text { analysis }\end{array}$ & $\begin{array}{c}\text { Coefficients of compo- } \\
\text { nents }\end{array}$ & $\begin{array}{c}\text { Coefficients of discrimi- } \\
\text { nant function }\end{array}$ & $\begin{array}{c}\text { Correlation coefficients of } \\
\text { variable and discriminant } \\
\text { score }\end{array}$ \\
\hline Residence & 0.706 & -0.482 & 0.198 & 0.278 \\
\hline Religion & 0.545 & 0.004 & -0.124 & -0.128 \\
\hline Age of child & 0.587 & -0.058 & 0.224 & 0.162 \\
\hline Gender & 0.539 & 0.23 & 0.076 & -0.362 \\
\hline Father's education & 0.791 & 0.885 & -0.456 & -0.063 \\
\hline Father's occupation & 0.681 & 0.794 & 0.026 & -0.276 \\
\hline Mother's education & 0.81 & 0.874 & -0.59 & 0.418 \\
\hline Mother's occupation & 0.555 & 0.63 & 0.617 & -0.418 \\
\hline Family income & 0.599 & 0.668 & 0.475 & 0.394 \\
\hline Food habit of child & 0.68 & 0.71 & 0.509 & 0.214 \\
\hline Utilization of time by the \\
child & 0.724 & -0.739 & 0.212 & 0.039 \\
\hline BMI & 0.844 & 0.099 & 0.114 & \\
\hline
\end{tabular}

As there were two levels of prevalence of diabetes, one discriminant function was derived. For two groups the mean vectors of the variables were significantly different as was observed by Box's M-test, where $\mathrm{M}=600.714$ leading $\mathrm{F}=7.472$ with $\mathrm{p}$-value $=0.000$. The discriminant analysis was significant as Wilks $\wedge=0.765, \chi^{2}=174.634, p$-value $=0.000$. From the results of the correlation coefficient of a variable with discriminant score it was noted that the most responsible variable for prevalence of diabetes was mother's occupation followed by family income and food habit of the children. Father's education was also responsible variable for prevalence of diabetes among the children and adolescents. These variables were identified from the highest absolute value of correlation coefficient of the variables and discriminant score. Body mass index was also responsible for severe obesity and diabetes. 
These variables were responsible for health hazard of the children and adolescents.

\section{Conclusion and Discussion}

The present analysis was done using the data collected from 662 children and adolescents of some affluent families of Bangladesh. The studied subjects were classified by level of obesity and by level of prevalence of diabetes. Among the investigated children and adolescent's 70.2 percent were underweight. The percentages of overweight, obese and severe obese were 20.7, 6.3 and 2.8, respectively. Again, 22.8 percent were diabetic. Higher (38.1\%) percentage of obese children and adolescents were diabetic compared to the diabetic respondents of other level of obesity. There was significant association between level of obesity and prevalence of diabetes. For the same group of respondent's significant association between level of obesity and different socioeconomic characters were noted [24,25] earlier. Similar association was also noted between prevalence of diabetes and socioeconomic variables. The present analysis was an attempt to identify the responsible variables for the variation in the level of obesity and in the level of prevalence of diabetes.

In a separate study it was noted that obesity and diabetes were significantly associated $[1,7,23]$. Child obesity and prevalence of diabetes were significantly associated with restaurant food [20] and also with non-participation in physical exercise and games and sports, rather killing the time by watching television $[24,25]$ Parents' social status were also associated with child obesity and diabetes $[24,25]$. The present study also indicated that parents' education, their occupation, family income, food habit of the children and adolescents and utilization of time by them were some of the most responsible variables for obesity and prevalence of diabetes.

Obesity and diabetes are interrelated phenomenon and these two can start at any time of the childhood and these persist even at old age. Unless these are not controlled and proper care is not taken to reduce obesity, anyone can face serious health problem leading to cardiovascular diseases, kidney problem, eye problem, gangrene, etc. This a problem for both parents and health planners. Parents can take care of food and utilization of time of their kids and can motivate them to reduce the rate of taking fast food from the restaurant. The children can be accompanied by the parent or by any elderly to the places where there are sufficient scopes for the body development and mental development of the child.

\section{References}

1. Elizabeth R Pulgarom, Alam M Delameter (2014) Obesity and Type 2 Diabetes in Children, Epidemiology and Treatment. Curr Diab Rep 14(8): 508.

2. Manu Raj, R Krishna Kumar (2010) Obesity in children and adolescents. Indian Jour.Medical Research 132(5): 598-607.

3. Reilly JJ (2006) Obesity in childhood and adolescence: evidence based clinical and public health perspective. Post Graduate Medical Journal 82(969): 429-437.

4. Biswas T, Islam A, Islam MS, Pervin S, Rawal LB (2017) Overweight and obesity among children and adolescents in Bangladesh:a systematic review and meta-analysis. Public Health 142: 94-101.
5. Hoque ME, Doi SA, Mannan M, Long K, Niessen LW, et al. (2014) Prevalence of overweight and obesity among children and adolescents of the Indian subcontinent : A meta-analysis, Nutrition Review 72(8): 541-550.

6. Sinha R, Fisch G, Teague B, Tamborlane WV, Banyas B, et al. (2002) Prevalence of impaired glucose tolerance among children and adolescents with marked obesity. N Engl J Med 346(11): 802-810.

7. Chris Wool Stem (2017) Type 2 Diabletes and Kids, The Growing Epidemic, Health Day.

8. Weiss R, Dzuria J, Burgert TS, Tamborlane WV, Taksali SE, et al. (2014) Obesity and the metabolic syndrome in children and adolescents. N Engl J Med 350(23): 2362-2374.

9. Huang J, Gottschalk M, Norman G, Galfas K, Sallis J, et al. (2011) Compliance with behavioral guidelines for diet, physical activity and sedentary behaviors is related to insulin resistance among overweight and obese youth. BMC Res Notes 4: 29.

10. Pulgaron ER (2013) Child obesity: a review of increased risk for physical and psychological comorbidities. Clin Ther 35(1): A 18-A32.

11. Goodman E, Whitaker RC (2002) A prospective study of the role of depression in the development and persistence of adolescent obesity. Pediatrics 110(3):497-504.

12. Schwimmer JB, Burnwinkle TM, Varni JW (2003) Health related quality of life of severely obese children and adolescents. J Am Med Assn 289(14): 1813-1819.

13. Rolland Cachera MF, Dehgeer M, Maillot M, Bellisle F (2006) Early adiposity rebound: Causes and consequences for obesity in children and adults. Int J Obes 3(Suppl 4): S11-S17.

14. Gortmaker SL, Must A, Perrin JM, Sobol AM, Dietz WH (1993) Social and economic consequences of overweight in adolescence and young adulthood. New England J Med 329(14): 1008-1012.

15. Williams SM, Goulding A (2009) A patterns of growth associated with development of excessive fatness in children and adolescents: a review of prospective studies. Obes Rev 14(8): 645-658.

16. Ketsantas P, Gaffney KF (2010) Risk profiles for overweight /obesity among preschools. Early Hum Dev 86(9): 563-568.

17. Hendrie GA, Coveney J, Cox DN (2011) Defining the complexity of childhood obesity and related behavior within the family environment using structural equation modeling. Public Health Nutrition 15: 48-57.

18. Elder JP, Arredondo EM, Campbell N, Baquero B, Duerksen S, et al (2010) Individual, family, and community environmental correlates of obesity in Latino elementary school children. J Sch Health 80(1): 20-30.

19. Epstien LH, Raja S, Daniel TO, Paluch RA, Wilfley DE, et al. (2012) The built environment moderates' effects of family-based childhood obesity treatment over 2 years. Ann Behav Med 44(2): 248-258.

20. Currie J, Della Vigna S, Moretti E, Vikram Pathania (2010) The effect of fast food restaurants on obesity and weight gain, American Economic Journal: Economic Policy 2: 32-63.

21. Block JL, Macinko J (2008) Neighbourhoods and obesity. Nutr Rev 66(1): 2-20.

22. Sallis JF, Zakarian JM, Hovell MF, Hofstetter R (1996): Ethnic, socioeconomic and sex differences in physical activity among adolescents. J Clin Epidemol 49(2): 125-134.

23. Jannatul Fardus, Bhuyan KC (2016) Discriminating diabetic patients of some rural and urban areas of Bangladesh: A discriminant analysis approach, Euro mediterrean Biom Jour 11(9): 134-140.

24. Urmi FA, Bhuyan KC (2018) Obesity in children and adolescents and the factor responsible for it: A case study among children of some affluent families. Int Diab Card Dis 2(1): 56-66. 
25. Bhuyan KC, Urmi FA (2018) Identification of factors responsible for obesity in children and adolescents of some affluent families. BJSTR 10(5): 8121-8129.

26. Mahfuza K, Bhuyan,KC (2014) Awareness of health hazard of tobacco consumption among students of American International University Bangladesh. AJSE 13(1): 85-92.
27. Bhuyan KC (2004) Multivariate analysis and its Applications, New Central Book Agency (Pvt) Ltd, India.

28. Bhuyan KC (2019) A note on the application of discriminant analysis in medical research. Archives of diabetes and obesity 2(2): 142-146. 